\title{
Growth Characteristics and Tree-Ring Width Response of Quercus acutissima to Climate Factors in the Rocky Mountain Area of Northern China
}

\author{
Yu Liu', Peng Gao ${ }^{1 *}$, Jian Ni Sun${ }^{1}$, Xiang Niu², Rong Jia Wang ${ }^{1}$ \\ ${ }^{1}$ Shandong Agricultural University/Mountain Tai Forest Ecosystem Research Station of State Forestry \\ Administration/Shandong Provincial Key Laboratory of Soil Erosion and Ecological Restoration, \\ Tai'an, Shandong, 271018, China \\ ${ }^{2}$ Research Institute of Forest Ecology, Environment, and Protection, Chinese Academy of Forestry, \\ Beijing Collaborative Innovation Center for Eco-environmental Improvement with Forestry and Fruit Trees, \\ Beijing 100091, China
}

Received: 24 December 2016

Accepted: 29 March 2017

\begin{abstract}
In order to investigate the effects of climate factors on the tree-ring width of Quercus acutissima in the rocky mountain area of northern China, correlation analysis and response function analysis were used to determine the relationship between the tree-ring width of Quercus acutissima and climate factors. The results showed that:

1. The residual (RES) chronology of the Quercus acutissima forest contained richer environmental information than standard (STD) chronology and was suitable for response analysis.

2. Tree-ring width had a general positive correlation with the average monthly temperature, a significantly positive correlation $(\mathrm{P}<0.05)$ with the April temperature, and a highly significantly positive correlation $(\mathrm{P}<0.01)$ with the May temperature of the current year. Tree-ring width had a positive correlation with precipitation from March to June in the current year, especially a significantly positive $(\mathrm{P}<0.05)$ correlation with May and June precipitation, and a negative correlation with precipitation from September of the previous year to February of the current year; however, the correlation coefficients with precipitation were basically lower than the coefficients with temperature basically

3. Temperature and humidity index were the main climate factors that influenced the tree-ring width of Quercus acutissima, followed by precipitation.
\end{abstract}

Keywords: tree-ring width, Quercus acutissima, climate factors, correlation analysis, response function analysis

*e-mail: gaopengy@163.com 


\section{Introduction}

With the frequent occurrence of abnormal climate in recent years, increasing attention has been paid to climate change. The tree-ring width is an important index that is used to evaluate the growth of trees, and tree-ring growth is the result of the combined effect of biological characteristics and external environmental conditions [1-3]. Tree rings have characteristics that include accurate dating ability, strong continuity, and high resolution, and have been widely used in research on climate change response for a long time [4-5]. Tree rings not only record the age of trees but also the climate changes that occurred in the past, and the close relationship between climate factors and tree-ring width can also be used to determine future patterns of tree growth in the context of climate change [6-8]. The formation of annual tree rings in the growth process is affected by many climate factors in both the current and previous years, and these factors are particularly important for the formation and growth of tree rings [9-11]. Therefore, in the scientific study of tree rings, it is generally believed that tree-ring width responds to climate factors, and assessing tree-ring width is an effective method of studying the impact of climate factors on tree growth [12-14].

Researchers at home and abroad have conducted many studies on the response of tree-ring width to climate factors. Douglass established a special laboratory to study tree-ring width in the 1930 s and preliminarily demonstrated the relationship between tree-ring width and precipitation [15-17]. Since then, researchers have conducted detailed studies on tree-ring width and climate factors. In a study determining the influence of climate factors on the growth of tree species in Namibia, tree-ring width was positively correlated with precipitation and was negatively correlated with temperature. Precipitation was the main climate factor that influenced tree growth in this region [18]. In a study on the effects of environmental changes on tree-ring width in Siberia, increases in summer temperature and winter precipitation increased tree-ring width and vertical height of the trees, and the climate changes had a corresponding impact on tree structure and growth [19]. Based on the close relationship between tree growth and climate factors, Tolwinski et al. [20] established a tree growth model to analyse the effects of climate factors on tree-ring width. Over the past 50 years, the average temperature in central Europe increased by $2^{\circ} \mathrm{C}$, and researchers found that the increasing temperature reduced the utilization of soil water, thereby limiting treering width [21]. Based on Pearson's correlation coefficient, Primicia [22] found that increasing temperature could increase tree-ring width, but when the temperature caused drought stress it limited the growth of the tree rings. All of these studies show that climate factors have a certain impact on tree-ring width. Chinese studies on the relationship between tree-ring width and climate factors have also yielded productive results. A study conducted in the Huashan Mountain area showed a positive correlation between the tree-ring width of Pinus armandii and the temperature and high precipitation in spring, but a negative correlation with higher temperature was observed in June [23]. A study on the different age stages of Pinus taiwanensis showed that the main factor that affected tree-ring width was solar radiation when the cumulative temperature exceeded $10^{\circ} \mathrm{C}$ [24]. Based on density, image analysis, and isotope content, the relationship between the tree-ring width of larch and climate factors on the northern slope of Changbai Mountain in northeastern China was studied [25]. The results showed that temperature was the main factor that affected the width, and the response of larix to temperature differed at different altitudes. An artificial Chinese fir (Cunninghamia lanceolata) stand in the Dagangshan region of China was selected as a research object, and the growth of this species was studied in response to climate factors [26]. The results showed that the response of tree-ring width to temperature was not significant, but there was a significant response to precipitation, and the response coefficients of tree-ring width to climate factors were higher than the coefficients to temperature throughout the whole growth season. In the sub-alpine region of Sichuan Province, consistency was observed between the climate factors and the tree-ring width of Abies faxoniana at different altitudes; tree-ring width increased in response to the average temperature in June of the current year but was limited by the lowest temperature and precipitation [27].

In summary, studies on the response of tree-ring width to climate factors are mainly concentrated in the Loess Plateau of the northeastern and southern regions of China. Quercus acutissima is the typical vegetation and major species in the rocky mountain area of northern China and play an important role in controlling soil and water loss and in ecological vegetation restoration. While there are many studies on soil improvement and eco-hydrological benefits of Quercus acutissima forests in northern China [28-30], quantitative studies on the relationship between tree-ring width and climate factors are lacking. Therefore, it is difficult to accurately evaluate and scientifically determine the ecological protection effect of Quercus acutissima afforestation projects and the sustainable management of forest vegetation. In our study, Quercus acutissima in the Taiyi mountainous area in Shandong Province was selected as the research area; this region is a typical rocky mountain area of northern China. Correlation analysis and response function analysis were used to study the response of Quercus acutissima tree-ring width to climate factors to achieve the following objectives gradually: 1) to establish the standard (STD) chronology and residual (RES) chronology of Quercus acutissima forests, 2) to analyse the correlation between the tree-ring width of Quercus acutissima and climate factors, such as average monthly temperature and precipitation, and 3) to determine the response relationship between the tree-ring width of Quercus acutissima and climate factors and investigate the effects of climate factors on the tree-ring width of this species. This research can provide a scientific basis for vegetation structure regulation and management, as well as an evaluation of the ecological 


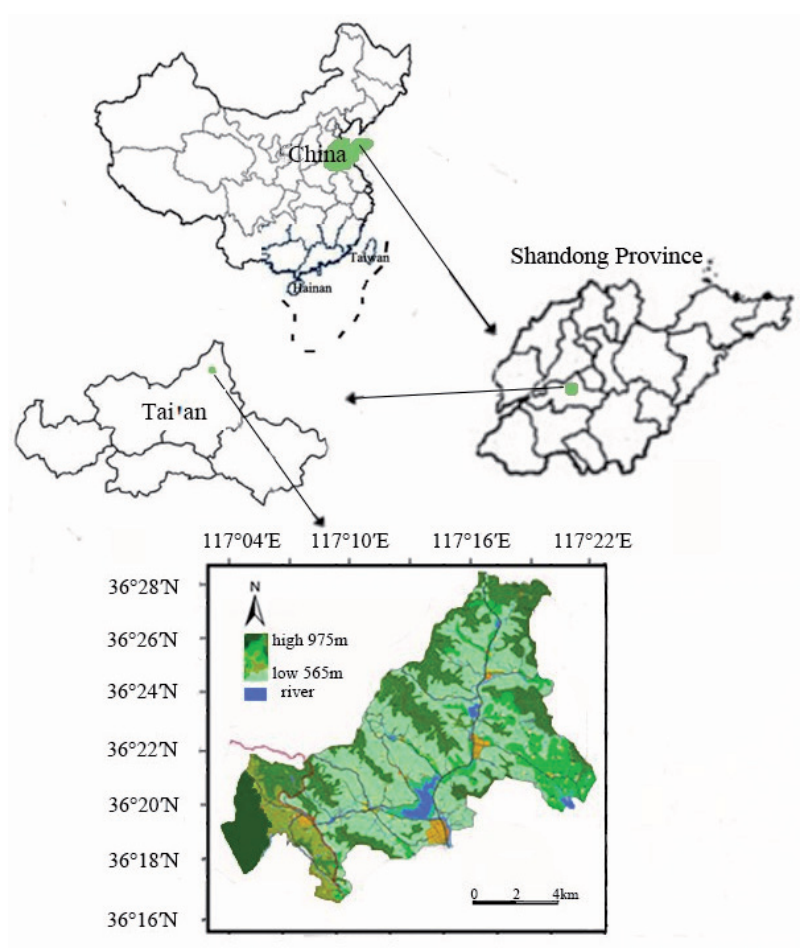

Fig. 1. Geographic location of the study area.

service function of pine and oak forests, not only in the rocky mountain area of northern China, but also in other parts of the world.

\section{Material and Methods}

\section{Study Area}

The study area is located in the Huangqian watershed of Tai' an City $\left(\mathrm{N} 36^{\circ} 16^{\prime}-36^{\circ} 28^{\prime}\right.$ and E117 $\left.04^{\prime}-117^{\circ} 22^{\prime}\right)$ in Shandong Province (Fig. 1), and covers a total area of $292 \mathrm{~km}^{2}$. The Huangqian watershed is located in the typical area of Taiyi Mountain and provides a very good representation of the rocky mountain area of northern China, with elevation ranging from $565 \mathrm{~m}$ to $975 \mathrm{~m}$. This area belongs to the warm temperate semi-humid monsoon climate, with an annual precipitation of $846.3 \mathrm{~mm}$. The average annual air temperature is $18.5^{\circ} \mathrm{C}$, the average annual maximum temperature is $34.6^{\circ} \mathrm{C}$, and the average annual minimum temperature is $-16.3^{\circ} \mathrm{C}$. The frost-free season lasts 196 days, and the soil is classified as brown soil. According to the results of a floristic-vegetational analysis (CAS, 2004), the vegetation types belong to coniferous forests and deciduous broad-leaved forests in the warm temperate zone, which include the following arbour species: Quercus acutissima, Pinus densiflora Sieb. et Zucc., Larix kaempferi, Castanea mollissima, and Robinia pseudoacacia; the main shrubbery species include Lespedeza bicolor Turcz, Vitis amurensis, Spiraea trilobata, Spiraea fritschiana Schneid., and Ziziphus jujuba var. spinosa (Bunge) $\mathrm{Hu}$; and the herbaceous species include Themeda triandra Forsk. var. japonica, Zoysia japonica, Bothriochloa ischaemum (L.) Keng, and Artemisia lavandulaefolia DC.

\section{Data Sources}

The area setup, observational indicators, and test methods of this work were based on the observation methodology for long-term forest ecosystem research, which was the Forestry Standards of the People's Republic of China (LY/T 1952-2011) [31]. Based on the international tree-ring database (ITRDB) standard, 28 Quercus acutissima trees in the study area were selected as samples. We obtained Quercus acutissima cores by drilling holes into the tree in the direction of the contour line or in a vertical direction along the slope. The cores were collected at chest height (usually $1.3 \mathrm{~m}$ ), and 2 to 3 cores were collected from every sample tree; a total of 56 sample cores were collected. Collected samples were immediately preserved in vitro, and the number, slope, altitude, and other related information were recorded (Table 1).

The meteorological data were obtained from the weather station that the Tai'an Meteorological Bureau established on Tai Mountain of the Huangqian watershed. This shation was located in the sample area of Quercus acutissima forests, with an elevation of $739 \mathrm{~m}$. Tai'an Meteorological Bureau, and the temperature, precipitation, and evaporation data from 1971-2015 were selected as a reference. The multi-year trend of the meteorological data (Fig. 2) showed that the precipitation was mainly concentrated in May-August, and the highest precipitation occurred in July, as did the highest average monthly temperature. Therefore, the study area experienced rain and heat in the same period over 6-8 months, and the average monthly temperature, precipitation, and evaporation data from September of the previous year to December of the current year (a total of 16 months) were collected for climate reference.

Table 1. Statistics of the sample trees of Quercus acutissima in the study area.

\begin{tabular}{|c|c|c|c|c|c|c|c|c|c|}
\hline Species & $\begin{array}{c}\text { Canopy } \\
\text { density }\end{array}$ & $\begin{array}{c}\text { Density } \\
\left(\text { plant.hm }{ }^{-2}\right)\end{array}$ & $\begin{array}{c}\text { Elevation } \\
(\mathrm{m})\end{array}$ & $\begin{array}{c}\text { Nomber } \\
\text { of trees }\end{array}$ & $\begin{array}{c}\text { Cores } \\
(\text { nomber })\end{array}$ & $\begin{array}{c}\text { Slope } \\
\left({ }^{\circ}\right)\end{array}$ & $\begin{array}{c}\text { Slope } \\
\text { direction }\end{array}$ & $\begin{array}{c}\text { Tree height } \\
(\mathrm{m})\end{array}$ & $\begin{array}{c}\text { Breast height } \\
(\mathrm{cm})\end{array}$ \\
\hline $\begin{array}{c}\text { Quercus } \\
\text { acutissima }\end{array}$ & 0.7 & 625 & $575-915$ & 28 & 56 & $20-26$ & $\begin{array}{c}\text { Southern } \\
\text { slope }\end{array}$ & 12.7 & $21-28$ \\
\hline
\end{tabular}

Based on the results of the cross-dating verification, 40 core-samples were selected for the establishment of tree chronologies after subtracting the samples with low correlation and too many singular points from the total samples. 


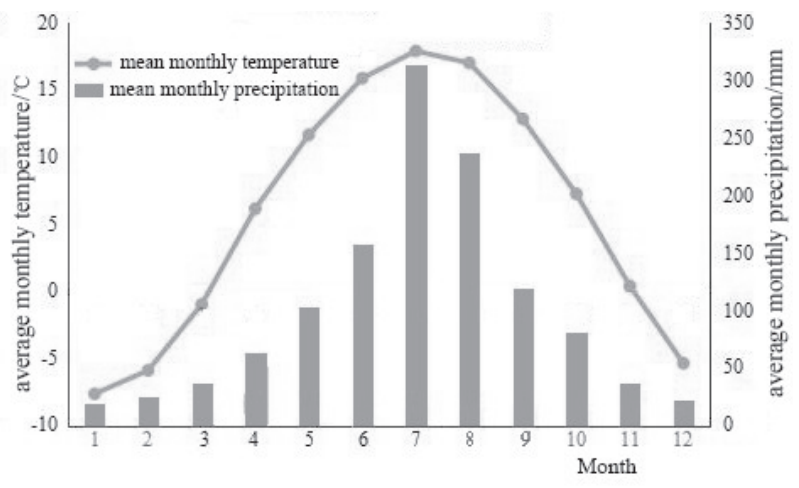

Fig. 2. Average monthly temperature and monthly precipitation during 1971-2015 in the study area.

\section{Data Analysis}

A skeleton diagram method was used to perform primary cross-dating of the cores after they were dried, fixed, and polished. Then the tree-ring widths were measured using the Lintab5 Ring Analyzer (Frank Rinn, Germany) with 0.01-mm accuracy. The width data were further tested using the COFFCHA program to identify dating errors to determine whether the sequence should be entered into the chronological table. The establishment of chronology was completed in the ARSTAN program, which first removed influences of the genetic factors, site conditions and other non-climatic factors, and matched the growth trends of the original tree-ring width. On the basis of the initial treatment, the age-related growth trend was eliminated using a spline function in the STD chronology. However, the effects of individual impacts and pre-physiological conditions on late growth were eliminated in the newly constructed RES chronology, as much as possible to keep the high-frequency changes of climate. Moreover, a common interval analysis of

Table 2. Statistics of tree-ring width and standard chronology of Quercus acutissima.

\begin{tabular}{|c|c|c|}
\hline Statistics & STD & RES \\
\hline Mean tree-ring widths & 0.98 & 1.16 \\
\hline Standard deviations & 0.27 & 0.15 \\
\hline Mean sensitivity (MS) & 0.24 & 0.30 \\
\hline Signal-to-noise ratios (SNRs) & 32.69 & 38.08 \\
\hline $\begin{array}{c}\text { First-order autocorrelation coefficients } \\
\text { (FOACs) }\end{array}$ & 0.17 & 0.12 \\
\hline $\begin{array}{c}\text { Overage correlation coefficient between } \\
\text { trees (ACCBTs) }\end{array}$ & 0.52 & 0.57 \\
\hline Variance of first principal components & 0.54 & 0.58 \\
\hline
\end{tabular}

STD represents the standard chronology of Quercus acutissima and RES represents the residual chronology of Quercus acutissima.
1971-2015 was performed on the STD and RES chronologies to determine which chronology was more suitable for the correlation analysis. In order to comprehensively evaluate the influence of climatic factors on the annual rings, the correlation and response function analyses were used to reveal the relationship between the tree-ring width of Quercus acutissima and climate factors. Therefore, this study used the chronology and the annual climatic factors data, such as $T_{i}, P_{i}, H_{i}$, and $E_{i}$ to establish the regression equation and conduct the $95 \%$ confidence interval test in order to quantitatively reveal the response relationship between the tree-ring width of Quercus acutissima and climate factors.

\section{Results}

\section{Statistical Characteristics of Quercus acutissima Forest Chronology}

To evaluate the quality of the tree chronologies, basic statistics of the tree-ring width sequences were calculated (Table 2). The statistical analysis of the characteristics of the Quercus acutissima forest chronologies showed that both the STD and RES chronologies exhibited good correlation among their respective sequences, which was the result of similar environmental factors. The mean sensitivity (MS) exceeded the acceptable level (0.1) and indicated that the Quercus acutissima forest was sensitive to the climate factors in the study area. In addition, the common interval analysis of 1971-2015 showed that the overall sample representativenesses exceeded the acceptable level of 0.85 . In addition, the signal-to-noise ratios (SNRs) were large (32.69 and 38.08 for the STD and RES chronologies, respectively), and the first-order autocorrelation coefficients (FOACs) were low (0.17 and 0.12 for the STD and RES chronologies, respectively). Thus, it can be concluded that although the response of the tree-ring width of Quercus acutissima to climate factors was not as good as that observed in arid areas (Wang et al. 2009), the response was also observed to a certain extent. The RES chronology contained richer environmental climate information and better represented the overall change in the study area (Table 2). Therefore, the RES chronology can be used as a substitute for the response analysis of Quercus acutissima to climate factors. However, the various RES chronology statistics only reflected the quality of the chronology and could not directly explain the correlation relationship; this relationship needs to be further studied using correlation analysis of RES chronology and climate factors.

\section{Correlation Analysis of Quercus acutissima Tree-Ring Width and Climate Factors}

Correlations analysis of Quercus acutissima tree-ring width and average monthly temperature. According to the correlation statistics between the treering width of Quercus acutissima and the average monthly 


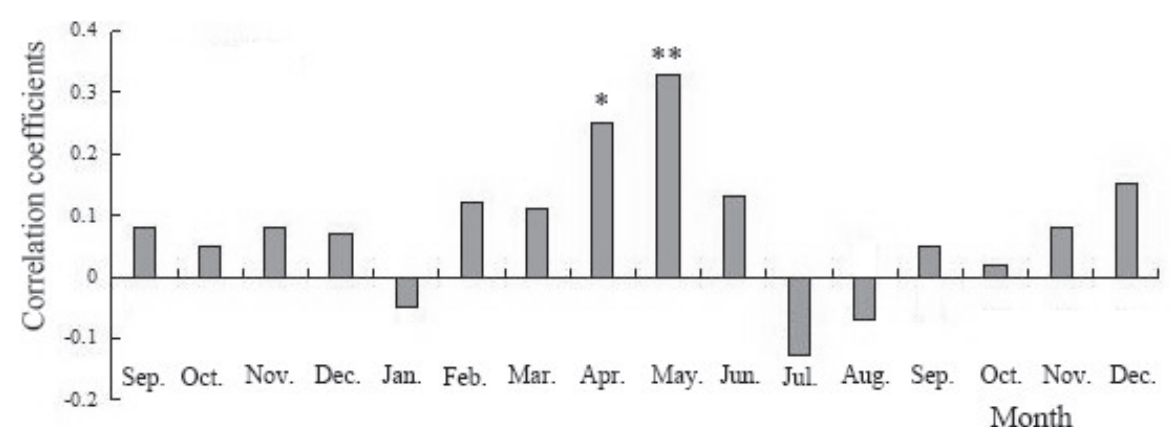

Fig. 3. Correlation coefficients between tree-ring width and average monthly temperature of Quercus acutissima. *significant correlation at $\mathrm{p}<0.05, \quad{ }^{* *}$ highly significant correlation at $\mathrm{p}<0.01$

temperature (Fig. 3), it can be concluded that the treering width was generally positively correlated with the average monthly temperature. In particular, tree-ring width was positively correlated with temperature at the end of the previous year and with temperature in spring of the current year. In addition, an especially significantly positive correlation $(\mathrm{P}<0.05)$ was observed with the April temperature, and a highly significantly positive correlation $(\mathrm{P}<0.01)$ was observed with the May temperature. However, the tree-ring width was negatively correlated with the July and August temperatures. In general, the correlation coefficients corresponding to the temperature of the previous year were lower than those obtained for the growth season in the current year.

Correlation analysis of Quercus acutissima tree-ring width and average monthly precipitation. Fig. 4 shows that Quercus acutissima tree-ring width had a general positive correlation with the average monthly precipitation in spring of the current year and a negative correlation with precipitation at the end of the previous year. In particular, the tree-ring width was positively correlated with precipitation from March to June of the current year, significantly positively correlated $(\mathrm{P}<0.05)$ with the May and June precipitation, and negatively correlation with the precipitation from September of the previous year to February of the current year. In general, the correlation coefficients corresponding to precipitation in the previous year were lower than those for the current growing season, and the correlation coefficients corresponding to average monthly precipitation basically were lower than those corresponding to the average monthly temperature.

\section{Response Function Analysis Results for Quercus acutissima Tree-Ring Width and Climate Factors}

Response analysis of Quercus acutissima tree-ring width was performed using average annual temperature $\left(T_{i}\right)$, precipitation $\left(P_{i}\right)$, humidity index $\left(H_{i}\right)$, and evaporation $\left(E_{i}\right)$ (Table 3$)$. It can be concluded from Table 3 that tree-ring width was highly significantly correlated with $T_{i}(\mathrm{P}<0.01)$ and significantly positively correlated with $H_{i}$ and $P_{i}(\mathrm{P}<0.05)$, with correlation coefficients of $0.56,0.34$, and 0.19 , respectively. The correlation with $E_{i}$ was relatively poorer, and the correlation coefficient was -0.06 .

Based on the RES chronology, the Quercus acutissima tree-ring width was regressed against $T_{i}, P_{i}, H_{i}$, and $E_{i}$ to establish the response function equation and to analyse the response relationship. The regression equation was:

$$
\begin{gathered}
R_{i}=0.0421 H_{i}-0.0712 T_{i}-0.0344 P_{i}+0.0078 E_{i}+2.082 \\
(F=4.014, \mathrm{P}<0.05)
\end{gathered}
$$

To further verify the results, this equation was used to calculate the tree-ring width and to then contrast the calculated values with the measured values. By the contrast

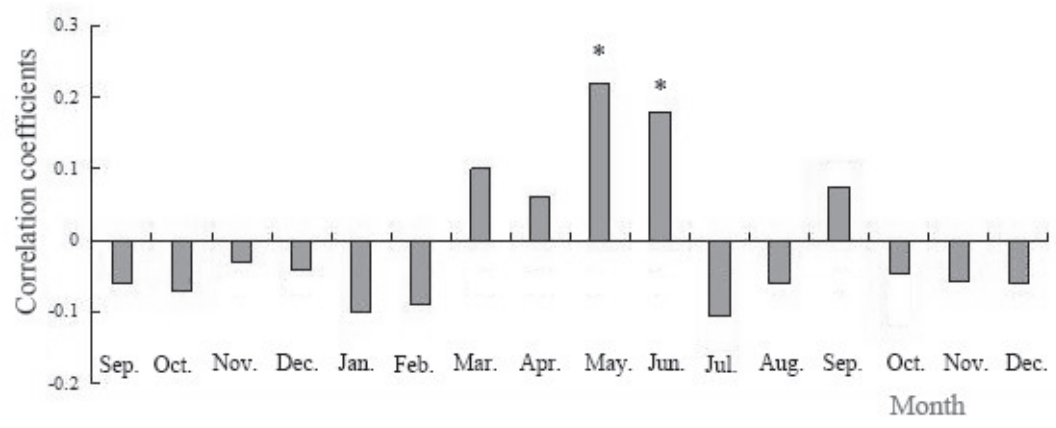

Fig. 4. Correlation coefficients between tree-ring width and average monthly precipitation of Quercus acutissima. "significant correlation at $\mathrm{p}<0.05,{ }^{* *}$ highly significant correlation at $\mathrm{p}<0.01$ 
Table 3. Correlation coefficients between tree-ring width and climate factors.

\begin{tabular}{|c|c|c|c|c|c|}
\hline Index & $R$ & $H_{i}$ & $T_{i}$ & $P_{i}$ & $E_{i}$ \\
\hline$R$ & 1 & $0.34^{*}$ & $0.56^{* *}$ & $0.19^{*}$ & -0.06 \\
\hline$H_{i}$ & $0.34^{*}$ & 1 & $-0.41^{*}$ & $0.92^{* *}$ & $-0.31^{*}$ \\
\hline$T_{i}$ & $-0.56^{* *}$ & $-0.41^{*}$ & 1 & -0.05 & $0.19^{*}$ \\
\hline$P_{i}$ & $0.19^{*}$ & $0.92^{* *}$ & -0.05 & 1 & $-0.23^{*}$ \\
\hline$E_{i}$ & -0.06 & $-0.31^{*}$ & $0.19^{*}$ & $-0.23^{*}$ & 1 \\
\hline
\end{tabular}

$R$ is the tree-ring width of Quercus acutissima forest; $T_{i}, P_{i}$, $H_{i}$, and $E_{i}$ are average annual temperature, precipitation, humidity index, and evaporation, respectively.

The humidity index $\left(H_{i}\right)$ can reflect the dry or wet situation by using the calculation of precipitation and temperature in an area. The formula is $H_{i}=P_{i} / T_{i}$, where $H_{i}$ is the humidity index and $P_{i}$ and $T_{i}$ are average annual precipitation and temperature, respectively, in the same period.

**a correlation test for 0.01 level

*a correlation test for 0.05 level

trend (Fig. 5), it can be concluded that the fitting degree of the equation between the calculated value and the measured value was acceptable $\left(r^{2}=0.75\right)$. This indicates that this equation is suitable for the estimation of Quercus acutissima tree-ring width in the Taiyi mountainous area and further proves the accuracy of the above analysis.

\section{Discussions}

\section{Effects of Average Monthly Temperature and Precipitation on Quercus acutissima Tree-Ring Width}

The correlation analysis of Quercus acutissima treering width and average monthly temperature (Fig. 3) indicated that the tree-ring width was positively correlated with the temperature from September to December in the previous year, but the correlation coefficients were low. This result is consistent with research on the response of the tree-ring width of Pinaceae tree species to climate factors in the Nanling region [32]. In the current study, the increasing temperature from September to December in the previous year increased the tree-ring width of Quercus acutissima, mainly because the growth of this species would slow down until the end of this period, but the trees can continue to photosynthesise and accumulate nutrients. At this time, the increasing temperature could improve the

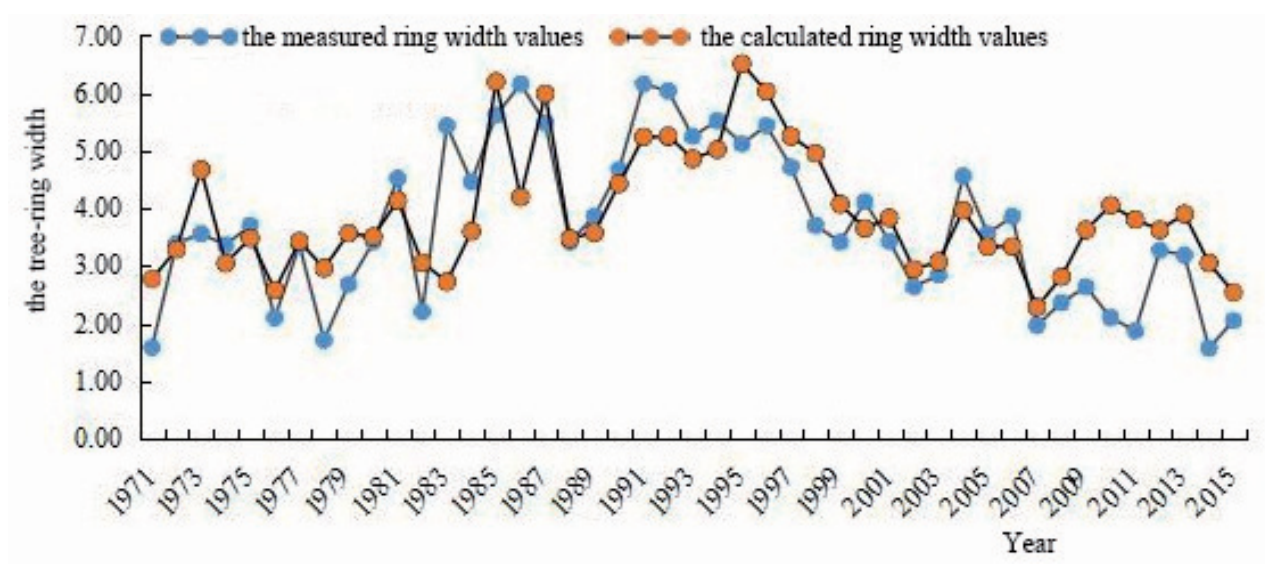

Fig. 5. Trends of calculated ring width and measured values.

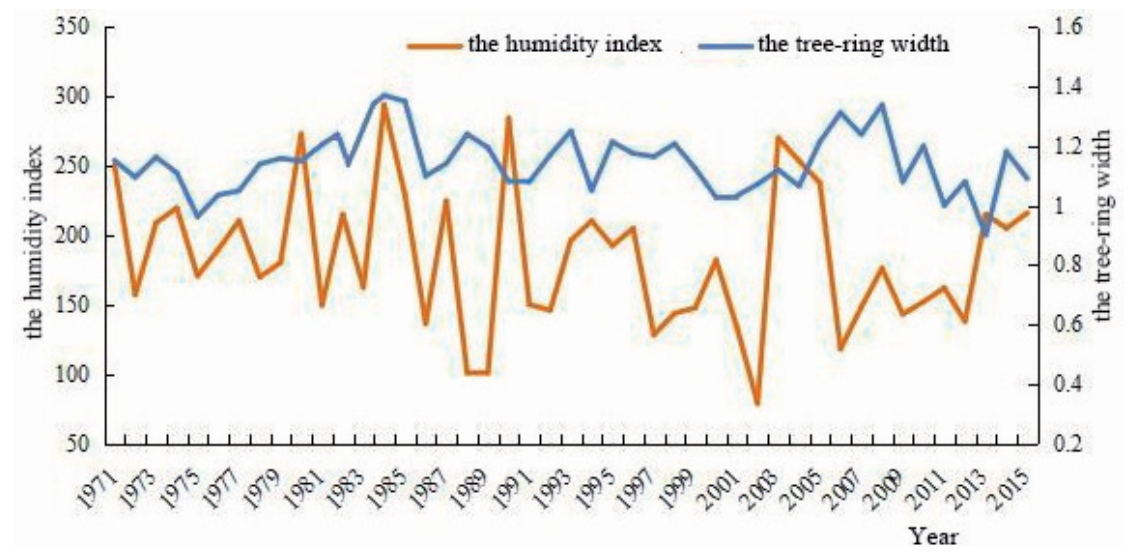

Fig. 6. Trends of tree-ring width and the humidity index. 
photosynthetic efficiency and provide more nutrients for growth in the following year. On the other hand, it was observed that the tree-ring width of Quercus acutissima had a positive correlation with the spring temperature in the current year (Fig. 3). This is consistent with the results presented for Larix Miller in China, i.e., a positive correlation with the temperature in spring [33]. From the perspective of plant physiology, as the temperature gradually increases in April, new leaves begin to develop and the xylem cells begin to divide and grow, which would promote the growth of Quercus acutissima and is conducive to the formation of earlywood. Consequently, tree-ring width was positively correlated with the temperature from April to June of the current year (Fig. 3 ), and these correlations were significant. However, in July and August, if the temperature continues to increase, metabolism may accelerate, increasing transpiration and limiting the growth of the forest. Fig. 3 shows that Quercus acutissima tree-ring width was negatively correlated with temperature from July to August, but the correlations were not significant.

Quercus acutissima tree-ring width was negatively correlated with precipitation from September to December of the previous year and from January to February of the current year (Fig. 4). This is consistent with the response of a Pinus massoniana forest to climate factors [34]. The results showed that excessive precipitation at the end of the previous year was not conducive to the accumulation of nutrients by Quercus acutissima. On the one hand, this was mainly because the excessive precipitation at the end of the previous year corresponded to high relative humidity and lower illumination, which reduced photosynthetic efficiency and resulted in the narrowing of tree-ring width; this effect could indirectly affect forest growth in the following year. On the other hand, precipitation during that time mainly supplemented the soil in the form of runoff or snow. This component of precipitation would not be fully used by the Quercus acutissima trees but would decrease the effect of temperature on tree growth. Therefore, the growth of the Quercus acutissima trees was negatively correlated with precipitation at the end of the previous year. In Hebei Province, a significantly positive correlation $(95 \%)$ was observed between precipitation in June of the current year and the ring width of Pinus tabulaeformis [35]. Similarly, in the current research, the tree-ring width of Quercus acutissima was positively correlated with precipitation from March to June of the current year. The Quercus acutissima forest entered the growing season in April; the monsoon climate increased the precipitation in the study area, and the temperature increased. Consequently, the plant growth requirements for water and heat could be met sufficiently, which greatly contributed to tree-ring width. In addition, the tree-ring width of Quercus acutissima was negatively correlated with precipitation in July and August of the current year, but the correlations were not significant. This occurred because the average monthly precipitation and temperature were higher during July and August (Fig. 2 ), and the excessive precipitation and relatively high temperature may have inhibited the growth of the Quercus acutissima forest.

\section{Combined Effects of Climate Factors, such as Temperature and Precipitation, on the Annual Tree-Ring Width \\ of Quercus acutissima}

Since tree growth is usually the result of multiple climate factors, a simple correlation between tree-ring width and climate factors characterize the response of tree-ring width to overall meteorological changes [36-37]. Response analysis was conducted using the chronology and the related corresponding climate factors to develop a multiple regression equation, revealing the response relationship between tree-ring width and multiple climate factors [38]. Based on the response analysis, it can be concluded that the tree-ring width of Quercus acutissima had the most significant correlation with $T$, followed by $H_{i}$ and $P_{i}$, but there was no significant with $E_{i}$ (Table 3 ). The results are in agreement with the relationship between climate factors and the growth of Pinus taiwanensis [24]. The Taiyi mountainous area is mainly affected by the monsoon climate. The East Asian monsoon brings abundant rainfall to this area during the growing season and consequently the rainfall can meet the demands of the Quercus acutissima forest for growth. Therefore, Quercus acutissima tree-ring width had a significantly higher correlation with $T_{i}$ and the combined effect $\left(H_{i}\right)$ of temperature and precipitation, but a lower correlation with $P_{i}$. This confirmed the results that tree-ring width had lower correlation coefficients with precipitation than with temperature in the correlation analysis. In conclusion, $T_{i}$ and $H_{i}$ were the main factors that influenced the tree-ring width of Quercus acutissima in the rocky mountain area of northern China, followed by $P_{i}$.

$H_{i}$ represents the degree of dryness and wetness in a region and is a reflection of the combined effect of temperature and precipitation. The results showed that the tree-ring width of Quercus acutissima was significantly correlated with $H_{i}$ (Table 3). The response of the treering width of Pinus sylvestris to climate factors, which was studied using correlation and response function analyses, indicated that tree-ring width was influenced by both precipitation and temperature, showing that Pinus sylvestris is a precipitation-sensitive tree type [39]. The reason for the difference between the above results may be that the annual precipitation $(349.3 \mathrm{~mm}$ ) could not meet the water demand of the Pinus sylvestris forest in Hulunbuir, where the soil water deficit is the factor that most strongly limits tree growth. Therefore, the tree-ring width of Pinus sylvestris was highly affected by precipitation. In our study area, the annual average precipitation was sufficient to meet the water demand of the Quercus acutissima forest; consequently, precipitation is not the main limiting factor of tree growth. The combined water and temperature demand of the Quercus acutissima forest resulted in a significant positive correlation between $H_{i}$ and tree-ring width. 
The variation trend of $H_{i}$ and RES chronology is presented in Fig. 6. It was observed that the change tendency of the peak-to-valley value of $H_{i}$ and RES exhibited good consistency, and the fitting degree was acceptable $\left(r^{2}=0.82\right)$. This result also proved the conclusion that Quercus acutissima tree-ring width was significantly correlated with $H_{i}$ in the response analysis. From Fig. 6, it was also found that the effect of $H_{i}$ on tree-ring width had a certain lag effect. For example, the changes in $H_{i}$ from 1993-97 and 2003-07 were consistent with the change trends of tree-ring width from 1995-99 and 2005-09, respectively. This occurred because the changes in climate factors, such as temperature and precipitation, were not reflected immediately in the annual tree-ring width of Quercus acutissima, resulting in a lag effect.

\section{Conclusions}

1. The statistical characteristics of the chronologies indicated that the STD and RES sequences exhibited good correlations with their respective samples, and the statistics indicated that the climate factors that affected tree-ring width could be extracted. The RES chronology of the Quercus acutissima forest contained richer environmental information than STD and was suitable for the response analysis.

2. The tree-ring width of Quercus acutissima had a general positive correlation with temperature: there was a significantly positive correlation with the average monthly temperature in April of the current year and a highly significantly positive correlation with the May temperature in the current year. As the spring temperature increased, the Quercus acutissima forest began to grow, and a higher spring temperature was more conducive to an increase in the tree-ring width of Quercus acutissima. The tree-ring width was negatively correlated with precipitation at the end of the previous year. This was mainly because precipitation at the end of the previous year corresponded with lower illumination, reducing photosynthetic efficiency; the tree-ring width exhibited positive correlation with the average monthly precipitation in spring of the current year.

3. Temperature and the humidity index were the main climate factors that influenced the tree-ring width of Quercus acutissima in the rocky mountain area of northern China, followed by precipitation, while evaporation had no significant effect on the Quercus acutissima forest. The results of the response function analysis of tree-ring width showed a good consistency between the calculated and measured ring-width values; thus, the response function was suitable for estimating the tree-ring width of Quercus acutissima in the study area.

\section{Acknowledgements}

This study was supported by the Special Fund for Forestry Scientific Research in the Public Interest (No. 201404303), the Natural Science Foundation of Shandong Province of China (No. ZR2016CM49), grants from the Beijing Municipal Education Commission (CEFFPXM2016-014207-000038), and the College Students Technology Innovation Plan Project in Tai'an City (No. 2015D034).

\section{References}

1. WANG M., BAI S.J., TAO D.L., SHAN J.P. Effect of rise in air-temperature on tree ring growth of forest on Changbai Mountain. Chinese Journal of Applied Ecology 6 (2), 128, 1995.

2. LENG L. The study on the response of contemporary tree ring width of Castanopsis fargesi and Cinnamomum camphora to climate change in Dagangshan. MS. Thesis, Chinese academy of forestry, Beijing, 2007.

3. WANG Y.J., GAO S.Y. Reconstructing the annual precipitation varitaion since 1899 based on tree-ring width in the western Hedong sandy land of Ningxia. Journal of Arid Land 2, 286, 2010.

4. HUGHES M. K, KELLY P. M, PILCHER J. R, LAMARCHE JRVC. Climate from Tree Rings. Cambridge University Press, New York, 1982.

5. DAVIES B.T., VALDES P.J., JONES C.D., SINGARAYER J.S. Sensitivity of a coupled climate model to canopy interception capacity. Climate Dynamics 42 (7), 1715, 2014.

6. BIGLER C., RIGLING A. Precision and accuracy of treering-based death dates of mountain pines in the Swiss National Park. Trees. 27, 1703, 2013.

7. BONTEMPS J.D., GELHAYE P., NEPVEUG., HERVE J.C. When tree rings behave like foam: moderate historical decrease in the mean ring density of common beech paralleling a strong historical growth increase. Annals of Forest Science 70, 329, 2013.

8. TEI S., YONENOBU H., SUZUKI S., OHYAMA M., GOTANDA K., NAKAGAWA T., SUGIMOTO A. Reconstructed July temperatures since AD 1800, based on a tree-ring chronology network in the Northwest Pacific region, and implied large-scale atmospheric-oceanic interaction. Palaeogeography 435, 203, 2015.

9. WANG T., YU D., LI J.F., MA K.P. Advances in research on the relationship between climatic change and tree-ring width. Acta phytoecologica sinica 27(1), 23, 2003.

10. CAI Q.F., LIU Y., YANG Y.K., SHI J.F., SUN J.Y., WANG L. The reconstruction of tree ring chronology and early spring (from February to March) precipitation information in Huanglong region, Shaanxi province. Marine geology \& quaternary geology $\mathbf{2 5}$ (2), 133, 2005.

11. YAO Q.C., WANG X.C. Climate-growth relationships of Abies nephrolepis and its connection with large-scale climate change in Xiaoxing'an Mountains, northeastern China. Journal of Beijing Forestry University 35 (2), 30, 2013. 
12. XING Q.R., LIU H.Y., SUN Y.R., CUI H.T., LI P.R., TAN H.Z. Response of contemporary tree-ring width of Cinnamomum camphora to climate change in Yangchun, Guangdong province. Acta ecologica sinica 24 (9), 2077, 2004.

13. ZHENG S.X, SHANGGUAN Z.P. Study on relationship tree-ring and climatic change. Scientia silvae sinicae 42 (6), 100, 2006.

14. ZHENG G.Y., WANG W.J., WANG X.C., YU J.H., LIU D., ZU Y.G. Tree-ring climatology of Larix gmelinii in Maoershan region, Northeastern China. Bulletin of botanical research 32 (2), 191, 2012.

15. WILLIAMS A.P., STILL C.J., FISCHER D.T., LEAVITT S.W. The influence of summertime fog and overcast clouds on the growth of a coastal Californian pine: a tree-ring study. Oecologia 156, 601, 2008.

16. RICHARD J.C., THOMAS M.M., IAN T. ROB J.S.W., KEITH R.B. A tree reconstruction of East Anglian (UK) hydroclimate variability over the last millennium. Climate Dynamics 40, 1019, 2013.

17. OPALA M., MENDECKI M.J. An attempt to dendroclimatic reconstruction of winter temperature based on multispecies tree-ring widths and extreme years chronologies (example of Upper Silesia, Southern Poland). Theoretical and Applied Climatology 115, 73, 2014.

18. FICHTLER E., TROUET V., BEECKMAN H., COPPIN P., WORBES M. Climatic signals in tree rings of Burkea africana and Pterocarpus angolensis from semiarid forests in Namibia. Trees 18, 442, 2004.

19. DEVI N., HAGEDORN F., MOISEEV P., BUGMANN H. Expanding forests and changing growth forms of Siberian larch at the Polar Urals treeling during the 20th century. Glob Change Biology 14, 1581, 2008.

20. TOLWINSKI-WARD S.E., EVANS M.N., HUGHES M.K., AUCHUKAITIS K.J. An efficient forward model of the climate controls on interannual variation in tree-ring width. Climate Dynamics 36, 2419, 2011.

21. PÖTZELSBERGER E., WOLFSLEHNER B., HASENAUER H. Climate change impacts on key forest functions of the Vienna Woods. European Journal of Forest Research 134, 481, 2015.

22. PRIMICIA I. Age, competition, disturbance and elevation effects on tree and stand growth response of primary Picea abies forest to climate. Forest Ecology and Management 354, 77, 2015.

23. SHAO X.M., WU X.D. Tree-ring chronologies for Pinus armandi franch from Huashan, China. Acta geographica sinica 49 (2), 174, 1994.

24. WU Z.M., HUANG C.L., MA Q.S. Relationship between tree-ring growth of Pinus taiwanensis and climatic factors. Chinese journal of applied ecology 10 (2), 147, 1999.

25. YU D.P, WANG S.Z., TANG L.N., DAI L.M., WANG Q.L., WANG S.X. Relationship between tree-ring chronology of Larix olgensis in Changbai Mountains and the climate change. Chinese journal of applied ecology 16 (1), 14, 2005.

26. WANG B., GAO P., GUO H., LENG L. Responses of treering width of Cinnamomum camphora to climate change in Dagangshan forest area of Jiangxi Province. Chinese journal of applied ecology 20 (1),71, 2009.

27. ZHAO Z.J. Respones of Abies faxoniana of tree-ring to climate factor in sub-apline in Western Sichuan. MS. Thesis, Chinese academy of forestry, Beijing, 2013.

28. YU D.P. Study on eco-economic water and soil conservation forest benefit evaluation and model design in Westen Liaoning province. MS. Thesis, Shenyang agricultural university, Shenyang, 2001.

29. LI D.S. An study on hydrological characteristics of main vegetation types in Tai'an huangqian reservior area of Shandong China. PhD. Thesis, Chinese academy of forestry, Beijing, 2007.

30. HU J.P. Study on Soil and Water Conservation benefits of different patterns forests in Limestone Degraded Mountain in Middle-south of Shandong province. MS. Thesis, Shandong Agricultural University, Tai'an, 2012.

31. WANG B., LU S.W., LI H.J., NIU X. Observation methodology for long-term forest ecosystem research. State Forestry Administration: Beijing, China, 2011.

32. CAO S.J. The study on the response of tree ring width of Pinaceae tree species to climate factors and climate reconstruction in Nanling region. $\mathrm{PhD}$. Thesis, Central south university of forestry and technology, Changsha, 2015.

33. SUN Y., WANG L.L., CHEN J., DUAN J.P., SHAO X.M., CHEN K.L. Growth characteristics and response to climate change of Larix Miller tree-ring in China. Science chinaearth sciences 40 (5), 645, 2010.

34. DAI S.Z. Climate response analysis of Pinus massoninan tree-ring chronology. MS. Thesis, Nanjing Agricultural University, Nanjing, 2014.

35. CUI M.X, HE X.Y, CHEN W., CHEN Z.J., ZHOU C.H., WU T. Dengrochronology of chinese pine in Mulan-weichang, Hebei Province: A primary study. Chinese journal of applied ecology 19 (11), 2339, 2008.

36. XU X.D., SHAO X.M. A preliminary study on impact of climate change on treegrowth using tree ring-width data. Acta geographica sinica 51, 92, 1996.

37. SHENG X.J., WANG S.G., GUAN D.X., JIN C.J., WANG A.Z., WU J.B., YUAN F.H. Canopy interception in larch plantation: Measurement and modeling in Eartern Liaoning Mountainous Region. Chinese journal of applied ecology 21 (12), 3021, 2010.

38. CHEN L.Q, YU H.Y, YANG X., YANG P. Cryptomeria fortune tree-ring width index with responses to climate change in the southwestern of Sichuan. Journal of Sichuan agricultural university 30(3), 293, 2012.

39. SHANG J.X., SHI Z.J., GAO J.X., XU L.H., LV S.H., FENG Z.Y., WANG L.X. Response of tree-ring width of Pinus sylvestris var. mongolica to climate change in Hulunbuir sand land, China. Acta ecologica sinica 32 (4), 1077, 2012. 